\title{
A didática como diferenciador das diferenças pelas potências dos possiveis
}

\author{
Artur José Renda Vitorino* \\ http://dx.doi.org/10.1590/0103-7307201507610
}

\section{Resumo}

Ao imantar o positivo, a diferença, os fluxos, os agenciamentos expressões essas que denotam o que é vivo, a dobra e a redobra, a duração e os signos geradores de potencialidades -, o artigo interroga: como instalar na e pela multiplicidade das coisas vivas para aprender "a repetição como passagem de um estado das diferenças gerais à diferença singular, das diferenças exteriores à diferença interna - em suma, a repetição como o diferenciador da * Pontifícia Universidade Católica de Campinas PUC-Campinas, Faculdade de História, Programa de Pós-Graduação em Educação, Campinas, SP, Brasil. arturvitorino@ puc-campinas.edu.br diferença” (Deleuze, 1988, p. 136)? Ao buscar delinear, pelas potências dos possíveis, a didática como diferenciador da diferença, conclui-se que essa didática exerce um duplo papel: 1) mostra o conteúdo da força; e 2) permite as passagens entre virtual e atual, revelando, distintamente, a ontologia da pura diferença.

Palavras-chave: didática, diferença, Deleuze, questão dos possíveis., dramatização 


\title{
The didacticism as differentiator of the difference by the potency of possible things
}

\begin{abstract}
To magnetize the positive, the difference, the flux, the agencies - expressions which denote what is alive, the folding and the refolding, the duration and the generators signs of potentialities - the article asks: how to install in and by the multiplicity of the alive things to learn "the repetition as passage from a state of general differences to the singular difference, from external differences to internal differences, in short, the repetition as the differentiator of difference "(DELEUZE, 1988, p. 136)? In seeking to delineate, by the potency of possible things, the didactic as differentiator of the difference, it is concluded that this didactic plays a dual role: 1) shows the contents of the force, and 2) allows the passages between virtual and actual, revealing distinct one, the ontology of the pure difference.
\end{abstract}

Keywords: didacticism, difference, Deleuze, issues of the possible things, dramatization 
Para Luiz B. L. Orlandi

\section{Introdução}

No texto intitulado “Em que se pode reconhecer o estruturalismo”, Deleuze (19251995) afirmou que livro "algum contra o que quer que seja jamais tem importância: [itálico do autor] somente contam os livros ‘pró’ alguma coisa de novo, e que sabem produzi-lo" (Deleuze, 2006, p. 247).

O negativo e suas categorias - ou, como diria Foucault (1996), ao apresentar O anti-Édipo ao público estadunidense: “a lei, o limite, as castrações, a falta, a lacuna” - precisam ser deslocados para dar lugar ao que é "positivo e múltiplo, a diferença à uniformidade, os fluxos às unidades, os agenciamentos móveis aos sistemas" (p.199).

O positivo, a diferença, os fluxos, os agenciamentos, todas essas expressões denotam o que é vivo, a dobra e a redobra, a duração e os signos geradores de potencialidades. Mas como conseguir instalar na e pela multiplicidade dessas coisas vivas para aprendermos, por meio de uma espécie de didática, “a repetição como passagem de um estado das diferenças gerais à diferença singular, das diferenças exteriores à diferença interna - em suma, a repetição como o diferenciador da diferença" (Deleuze, 1988, p. 136)?

A obra de Gabriel Tarde (1834-1904) - especialmente as suas reflexões presentes em: Monadologia e sociologia, $A$ variação universal, $A$ ação dos fatos futuro e Os possíveis - ajuda-me a pensar a dialética da diferença e da repetição, ao mostrar que a repetição é o diferenciador da diferença, o que o permitiu fundar uma microssociologia encadeada numa cosmologia. E as pesquisas de Ilya Prigogine (2002), a partir do que ele denominou de "estruturas dissipativas", permitem-me aliar a cosmologia de Gabriel Tarde ao que é sabido da vizinhança entre ele e Deleuze. Pois, tal como em Prigogine, na cosmologia de Tarde, o decisivo não está na ordem ou na desordem noções estas caras para a ciência baseada no determinismo - que possibilitariam o desabrochar do equilíbrio e da estabilidade, e sim, o decisivo encontra-se no não equilíbrio, nas flutuações criadoras de possibilidades: a força do se.

Dizer se não é apenas lícito; é útil, é necessário; nenhuma lei teria sido descoberta e formulada pelo homem se ele não fosse dotado da faculdade de dizer se. Dizer se é o não-existente concebido, é o audacioso salto do espírito, sua emancipação fora do real, do 
presente, do passado, do futuro, no racional e no inteligível. Toda metafísica está em germe nesse monossilabo (Tarde, 2007, p. 196).

Em princípio, então, para Tarde, o monossílabo se anuncia que toda realidade é concebida contendo, essencialmente, um excesso de potência sobre o ato, um excesso que expressa a solidariedade do possível e do real incorporados um ao outro. E é justamente esse excesso da potência sobre o ato que constitui, para Tarde, o conjunto dos possíveis não realizáveis ou das certezas condicionais. Portanto, a inteligência dos fatos exige o conhecimento dos possíveis.

Na fórmula de Tarde, o "real é um dispêndio de possível" (Tarde, 2007, p. 212). Assim, a realidade é o que existe só uma vez e dura só um instante. Consequentemente, passado esse instante, toda realidade torna-se impossível. Por outro lado, a realização de todos os possíveis é impossível. Isso significa que todas essas outras realidades morrem.

Sempre que uma realidade morre, ela sepulta consigo seu cortejo de possíveis; mas também, sempre que uma realidade nasce, ela faz avançar em um grau seu cortejo de possíveis. Como não se pode conceber uma realidade sem virtualidade, isto é, sem um certo excesso de potência sobre o ato, a realização de todos os possíveis implica contradição[itálicos do autor]. No entanto, ela ocorreria se o mundo fosse infinito; ou melhor, a infinidade do mundo não seria outra coisa senão essa realização da totalidade dos possíveis. Mas, independentemente de qualquer outra consideração, o simples fato da mudança das coisas demonstra a limitação do Ser. A infinidade seria um obstáculo à mudança, assim como a ubiquidade impediria o movimento. Como então um Ser infinito, realização simultânea de todos os possíveis, poderia passar de um fenômeno a outro? 0 infinito deve ser imutável (Tarde, 2007, p. 214).

O que este texto se propõe a enfatizar é que a didática como diferenciador da diferença pensa o diverso como diverso, ou seja, reflete que, em nosso mundo, a diversidade natural aparece sob três aspectos que se recortam: a diversidade das espécies, a diversidade dos indivíduos que são membros de uma mesma espécie, a diversidade das partes que compõem um indivíduo. Encontram-se, aí, alojadas - como excesso de potência - a especificidade, a individualidade e a heterogeneidade. E uma das constantes mais profundas que atravessa essa cosmologia é denunciar tudo o que é 
tristeza, tudo o que é causa da tristeza, tudo o que tem necessidade da tristeza para afirmar seu poder. Em Lucrécio, Spinoza, Nietzsche, Tarde e Deleuze, esse mesmo fim é buscado e atingido.

\section{Problematizar a expressão profundidade}

Se estiver à procura das constantes profundas para viver entre os vivos, o que é profundidade? Como determinar o objeto especulativo e prático como profundo, em detrimento do que não é profundo? Qual é a positividade do profundo? E problematizar-se a partir do que e não sobre que. Não se tem a pretensão de olhar de cima. Sobre. O alerta de Montaigne (1984) é preciso: "São sempre os menos capazes que olham os outros de cima e voltam da luta cheios de orgulho e disposição” (p. 425). Por isso, eles são incapazes “de julgar a verdadeira superioridade. A obstinação e a convicção exagerada são a prova mais evidente da estupidez. Haverá algo mais afirmativo, resoluto, desdenhoso, contemplativo, grave e sério do que um burro?" (p. 425).

Partirei de uma intuição detectada pela nossa fé perceptiva: a tristeza me parece que é profunda, enquanto a alegria é superficial. Apesar de não se saber, ao certo, quais emoções provocam o riso e o choro, sentimos que a tristeza vem do fundo da alma. Quanto à alegria, parece que ela é fugaz e esvai-se como um arabesco no ar. Apresenta lugares sem espessuras.

Se há elementos comuns ao riso e ao choro - como o fato de serem ambos, em grande parte, incontroláveis e parecerem ser reações excessivamente intensas a algum movimento interno da alma -, concordo que, comparativamente, a causa do riso é mais difícil de descobrir, e sua razão não é tão clara.

Falarei do riso, então. E para isso, instalarei na multiplicidade do objeto, pois delimitar conceitualmente uma possível unidade do riso já é motivo de troça. Por que escrever de algo tão diminuto, se à nossa volta há, escancaradamente, coisas mais sérias e importantes?

Sugestão: que se faça uma hierarquia dos problemas, uma tábua de preocupações para serem resolvidas na ordem do tempo e, assim, na técnica da exclusão - técnica do isto ou isso ou aquilo na região da escolha potencialmente mostrada pelo $e$ : isto $e$ isso $e$ aquilo $e . . .-$, praticá-las conforme essa ordem, delimitando ainda, nessa hierarquia, o que seja particular, o que seja geral.

Desde já me parece que o riso como efeito serve de excelente parâmetro, dentre 
outros que é preciso estabelecer, para delimitar e distinguir o que seja geral, do que seja particular. Pois, não é à toa que a nossa manifestação, diante de algo apresentado em público, é rir, e, às vezes, sobre esse mesmo algo, estando em nossa particularidade, sozinhos, não rimos. Ou será que publicamente, sempre, ou quase sempre, eu me apresento como sendo o outro? Publicamente, o riso é um grande operador de filtragem das diferenças; particularmente, o riso emerge do corpo que desvela um si ambíguo, porque abre em si mesmo, na sua unidade reflexiva, uma multidão momentânea como espectadora. Por isso, também, a extrema dificuldade em separar o riso normal do patológico, porque o riso, assim, na particularidade, de antemão, rompeu com seus próprios limites internos.

Audácia e pretensão, vizinhadas pela praticidade, são o que, no mínimo, não faltam em uma ideia de hierarquia de preocupações assim sugerida. Todavia, ainda é possível a discussão geral dos problemas gerais? Além do que, o consenso alcançado é uma prática de poder, e gostaria muito de ver a praticidade do dissenso!

Mas, então, devo abolir as práticas ditas imediatistas? Algum medo de errar? A verdade, quando a colocamos no sentido de utilidade, está inter-relacionada com valores que o sujeito formulador ali deposita. Uma excelente maneira de escondermos os valores, publicamente, é não expor as nossas potências. Permanecer expectantes com os objetos? (E isto, se ainda consigo delimitar os objetos).

Fala-se em seriedade e em não seriedade. Seriedade. Qual é o sentido dessa expressão? A mim circunscreve, primeiramente, um problema. 0 caráter de sério também é obtido pelo merecimento da atenção, do cuidado, da consideração, da sua importância. No seu julgamento e na sua espacialidade, seriedade apresenta imbricada a noção de profundidade. Contudo, problemas se apresentam quando pergunto onde me localizo para afirmar que daqui, algo, outro ou isto aqui mesmo se mostra profundo. Necessito, então, da noção de superfície, do lugar sem espessura. 0 humor pode nos assessorar na revelação dessa superfície finíssima.

Incitarei a observação - atribuída a Aristóteles pelos antigos latinos, como presente no escrito De partibus animalium - pela qual os seres humanos são as únicas criaturas que riem. 0 riso advém das nossas características humanas; afora os ecos risíveis das hienas, dos macacos, dos papagaios, dos golfinhos, do cachorro que nos ri latindo, etc., com diferentes considerações. Bergson (1983) nos escreve que "não há comicidade fora do que é propriamente humano [itálico do autor]" (p. 12). 
Assim, por exemplo, se, ao vir uma vaca ruminando, rio, é porque me lembro de alguma pessoa que masca chicletes dessa maneira. Há também de se alojar na insensibilidade, na inteligência, daí, Bergson (1983) também afirmar que o "maior inimigo do riso é a emoção" (p. 12). Com outro exemplo: rimos de uma pessoa que tropeça e cai ou "sai de gatão", além de outros motivos - dentre os quais a rigidez do transeunte -, porque nos esquecemos, momentaneamente, de uma possível afeição, de uma piedade por essa pessoa.

O riso também expressa a sensação, alegre e desdenhosa, da nossa própria superioridade. As piadas desdenhosas, cujo efeito é o riso, são um exemplo de como rimos da afetação, da baixeza e da deformidade presentes no comportamento de alguém. E rimos como um efeito do escárnio. De uma súbita superioridade nossa com relação às fraquezas alheias.

Uma imitação, quando bem efetuada, também provoca o riso, porque nos faz lembrar dos trejeitos, de certa rigidez dos gestos, da dicção, do som que o imitador representa da coisa imitada. Inventariar todas as causalidades que possam trazer como efeito o riso é por demais quantitativo, dadas as contingências que geralmente penetram e quebram o possível efeito de comicidade, multiplicando esse possível efeito em mais causalidades.

Perdido no objeto, tendo a fazer digressões. Começo com um desvio, ajuntando ao tema do riso uma ressonância, que assim considero e que posso expor, que há entre a memória e a moral.

No seu Considerações intempestivas, Nietzsche (1976, p. 105) nos escreve que é por se instalar totalmente no esquecimento, que os animais abarcam e vivem na felicidade, nos dando como exemplo um rebanho pastando. De fato, nunca percebi, por exemplo, um galináceo qualquer chorando, triste; porém, Nietzsche teria sido menos feliz se tivesse nos dado como exemplo um cachorro. A literatura mesma nos ajuda a atestar a faculdade de memória do cachorro. Na Odisseia de Homero (1996), Argos, o "cão do intrépido Odisseu" (Canto XVII), foi o primeiro a reconhecer seu amo após 20 anos de sua partida para ílion e por esse esperou, sob condição de mau zelo, de sofrimento. Assim que obteve um simples contato com seu amo, pateticamente, morreu. Exemplo de fidelidade e, assim, de moral dado pela memória. E seres de moral são seres de esperança. Contudo, quanto a nós, ainda não há, com a nossa memória genética e nervosa, como permanecermos só na esperança e não colocarmos um fim de certeza para realizarmos algo efetivamente. 
Afinal, embutidos como estamos no "mundo da ciência" (aqui, banalmente pensado), temos a tendência de correlacionar a certeza com a verdade. Essa última tem sua certeza expressa pela enunciação analítica correspondente à experiência, sobre a qual o sujeito cognosciente se debruçou, e, ordenadamente assim construída, configura-se como teoria, levando-nos ao senso de previsibilidade, dado que a natureza foi apreendida em sua ordem legal, pela qual é verdadeiro aquilo que está enunciado na teoria e que funciona exteriormente a esse simbolismo lógico-formal.

Essa é uma ideia confortante e segura para o conhecimento de interesse técnico. Porém, se transferida para o conhecimento de interesse emancipatório, este a tornará contraditória por si mesma, pois estarei cristalizando uma ordem natural e, assim, cair-se-á num mundo fechado, totalitário.

Há um tema mais religioso do que o tema da espera? Kant (1998, p. 31), ao prescrever o campo da filosofia perante a significação cosmopolita, ao interrogar "o que me é permitido esperar?", registrou que a religião responde à questão. Sobre os fins gerais: há uma boa política que não espera, mesmo que não seja uma espera passiva, uma Cidade dos Justos? Enfim, há ricocheteios que proliferam entre a memória e a moral, sendo vizinhadas pela espera/esperança, pela religiosidade. Será isso, dentre outros bálsamos, que me ajuda a atarracar as indeferidas infelicidades? Seres infelizes variavelmente costumam enrugar a tez das suas fisionomias, muito diferente do ativo exercício muscular facial - e até de corpo inteiro - ocasionado pelos sorrisos, risos, gargalhadas.

Se for estabelecido um eixo horizontal de durabilidade e beleza nos sorrisos, risos, gargalhadas, podemos dizer que, enquanto o eixo da duração é crescente - nesta ordem dita -, o da beleza, é decrescente. Assim, o sorriso é o mais belo dos três efeitos e também o mais rápido, fugaz, conseguindo essa simplicidade única por se instalar plenamente no instante. Por não ocorrer nele um efeito sonoro (os sorrisos são silenciosos), e, sim, somente um efeito de imagem, dado pelo toque de amizade, podemos pela percepção carregá-lo na memória. Os sorrisos brotam para serem ingenuamente percebidos e são os únicos que, às vezes, mantêm a mesma estatura estética dos olhares.

Os risos delimitam, por assim dizer, uma região entre os sorrisos e as gargalhadas. Eles penetram nas bordas dos sorrisos e das gargalhadas e, sendo um líquido miscível (humore), torna-se difícil distinguir onde termina um e onde começa o outro. Os risos mostram-se efêmeros na duração e perspicazes na sua beleza. Publicamente, são barulhentos para que o seu agente demonstre a sua inteligência e crítica em oca- 
siões assim testadas. Chateia-me, e isto, a qualquer um, quando sou objeto do riso, quando não o provoco deliberadamente, conscientemente e, mesmo assim, o efeito descobre-se hilariante.

Já as esganiçantes gargalhadas são feias e barulhentas. De longa duração - quando comparadas aos outros efeitos do riso e do sorriso -, elas podem, às vezes, lançar todo o corpo num movimento disjuntivo, furtando-se de uma possível arte harmônica. Quando substituem os movimentos peristálticos, sugerem a simbolização de perda de uma presa, mostrando a boca animalescamente predatória.

Uma investigação mais apurada sobre os risos precisaria perscrutar o seu contato psicológico, social, linguageiro. Numa primeira detecção, este objeto - os risos - é escorregadio: como uma bola de sabão, funda um ludismo aí implicado. O fenômeno do riso pode nos ajudar a tecer concepções gerais a respeito da natureza humana.

Se ainda transpassar, perpendicularmente, um eixo vertical na região ocupada pelos risos e dando-lhes um sentido de profundidade, encontrarei as alegrias e, por fim, as felicidades. As alegrias se figuram pelo seu estado de serenidade, de repouso. Nesse estado de espírito mais prolongado, o corpo não precisa, necessariamente, rir para mostrar-se alegre. Na região das felicidades cintila em cada um de nós, em cada singularidade, um ponto nodal semovente. Inevitavelmente, somos presos na misteriosa busca desse ponto, e é isso que nos corporifica como sendo homens vivos. Nas palavras de santo Agostinho, recolhidas por Constantin Noica (2011), “há em nós algo mais profundo do que nós mesmos" (p. 9).

Indubitavelmente, o homem é um animal esquisito. Em uma dessas esquisitices, entre outras, estão o sorrir, o rir, o gargalhar. Ainda: o estado de tristeza - estado de ação reativo - advém da estreiteza do espírito e não do seu contrário; o alargamento do espírito traz a afirmação, a ação ativa, me libertando das superstições para assim praticar a verdadeira distinção entre o que é finito e o que é infinito, especulado por esse espírito ativo.

\section{Os signos e a aprendizagem}

Essas manifestações do múltiplo como múltiplo, do diverso como diverso, que estão presentes no mundo e nas coisas, levam-nos a aspirar - incitados pela curiosidade - produzir conceitos com o fim de aprender. E aprender - de acordo Gilles Deleuze (2010, p. 4, destaques do autor), ao comentar Marcel Proust, 
diz respeito essencialmente aos signos. 0s signos são objeto de um aprendizado temporal, não de um saber abstrato. Aprender é, de início, considerar uma matéria, um objeto, um ser, como se emitissem signos a serem decifrados, interpretados. Não existe aprendiz que não seja "egiptólogo" de alguma coisa. Alguém só se torna marceneiro tornando-se sensível aos signos da madeira, e médico tornando-se sensível aos signos da doença. A vocação é sempre uma predestinação com relação a signos. Tudo que ensina alguma coisa emite signos, todo ato de aprender é uma interpretação de signos ou de hieróglifos.

Ao recolher da Recherche de Proust os signos mundanos, os signos amorosos e mesmo os signos sensíveis, Deleuze me indica que todos esses signos se aproximam da essência. Mas somente os signos da arte são capazes de me revelar a essência. E é a "essência que constitui a verdadeira unidade do signo e do sentido; é ela que constitui o signo como irredutível ao objeto que o emite; e é ela que constitui o sentido como irredutível ao sujeito que o apreende. Ela é a última palavra do aprendizado ou a revelação final" (Deleuze, 2010, p. 36).

Apesar do costume de compreender que a essência significa a unidade das coisas, a essência que nos é revelada pela obra de arte é uma diferença, a diferença última e absoluta. Sob o prisma de Deleuze (2010), é a diferença “que constitui o ser, que nos faz concebê-lo. Porque só a arte, no que diz respeito à manifestação das essências, é capaz de nos dar o que procurávamos em vão na vida” (p. 39).

A arte nos permite aprender que as essências já estavam em todas as espécies de signos e em todos os tipos de aprendizado. Por isso, a didática como diferenciador da diferença, ao realizar uma dobra sobre ela mesma, ou seja, ao empreender uma didática da didática, revela que a aprendizagem não está na mediação entre o sujeito e o objeto, como propõem as didáticas presas ao ensino de algo. Como as essências são alógicas ou supralógicas, ultrapassando tanto os estados da subjetividade quanto as propriedades do objeto, não há o espaço intervalar a mediar sujeito e objeto. Há os seres sensíveis aos signos. E ser sensível aos signos, considerar o mundo como coisa a ser decifrada, é um dom.

Se aprender diz respeito, essencialmente, aos signos, essa aprendizagem é algo a ser ensinado, tomando-se a expressão no sentido escolar de atribuir ao ensino a capacidade de ensinar os conteúdos e fornecer - àqueles aos quais nos propomos cuidar - a formação em suas dimensões cognitivas, morais, éticas, políticas (Cordeiro, 2006, p. 11)? 
Assim como a expressão “'aprender a aprender’ é opaca, não diz nada, não significa nada, talvez por ser 'auto-referencial’” (Azanha, 2006, p. 18), também padece de significação, é vazia, a sentença "ensinar a aprender os signos".

A didática como diferenciador da diferença não confere que o seu núcleo esteja somente na relação escola e ensino. Ela não assume que haja um núcleo. Mas isso não significa que ela ignore as contribuições dos diversos campos do conhecimento que se ocupam de discutir a educação como centrada nas expressões escola, ensino e magistério. Imanta-se que para além da escola, ensino e magistério há outras linhas de força no campo da didática diferenciadora de diferença. Há, por exemplo, as pedagogias multiplicadas (Cordeiro, 2003).

Ao folhear as inúmeras revistas existentes nas bancas de jornal, há presentes, em cada página, diversos agenciamentos didáticos nas propagandas, editoriais, cartas dos leitores, matérias, resenhas, opiniões, os quais incitam os contornos a construir modos de ser, agir, pensar, desejar, etc. Esses agenciamentos emitem signos que são objeto de um aprendizado temporal, não de um saber abstrato. E pela concentração, nesses agenciamentos, de tantos signos em um espaço tão reduzido e em tão grande velocidade, de um momento para outro eles evoluem, imobilizam-se ou são substituídos por outros signos.

Desta feita, aprendemos com os amores, com as amizades, com as coisas, e, especialmente, com as artes.

\section{Didática como dramatização}

Há o problema: a didática como diferenciador da diferença realiza as passagens entre virtual e atual? Ou seja, ela determina, como um espaço intensivo, o duplo aspecto da diferençação, qualitativa e quantitativamente (qualidades e extensos, espécies e partes)?

Tecnicamente, a didática, aqui, deve ser compreendida como o movimento da dramatização, no sentido atribuído por Deleuze (2006, p. 129-154). Ao considerar que a questão que é? não assegura descobrir a essência ou a ideia, para Deleuze (2006), é "possível que questões do tipo: quem?, quanto?, como?, onde?, quando?, sejam melhores - tanto para descobrir a essência quanto para determinar algo mais importante concernente à Ideia” (p. 129).

Assim, há duas séries a descrever. Numa delas, os dinamismos espaço-temporais, em suas várias propriedades, figuram o movimento de dramatização. 
Sob a dramatização, a Ideia encarna-se ou atualiza-se, vem a diferençar-se. [itálico do autor]. É ainda preciso que a Ideia, em seu conteúdo próprio, já apresente características que correspondam aos dois aspectos da diferençação. Com efeito, nela mesma, ela é sistema de relações diferenciais repartição de pontos notáveis ou singulares que resultam dessas relações (acontecimentos ideais). Quer dizer: a Ideia é plenamente diferenciada nela mesma, antes de se diferençar no atual [itálico do autor] (Deleuze, 2006, p. 130).

É precisamente, nesse ponto, que o método da dramatização, para Deleuze, é representado pelo conceito complexo de diferenciação/ diferençação. E é aqui que a didática como diferenciador da diferença permite, a meu ver, as passagens entre virtual e atual, ao trabalhar a produção de combinações praticamente ilimitadas de conglomerados finitos de componentes próprios a delimitar a "ocasião atual” (conceito este de Whitehead e retomado por Deleuze em A dobra - Leibniz e o barroco, de 1988).

Apesar de Deleuze, entre outros filósofos da diferença, nos propor o problema da dissolução da forma-Homem, e caso se pense que a forma-Homem são Ideias, multiplicidades que devem ser percorridas pelas questões como?, quanto?, em qual caso?, então, há a imantação da forma-Homem em seu sentido virtual, ou seja, a transmutação da forma-Homem em Ideia-Homem, que a faz cintilar como acontecimentos ideais, pois ela é, agora, uma “imagem sem semelhança” (Deleuze, 2006, p. 137), cuja atualização - explicita Deleuze (2006) - "é sempre criadora em relação ao que ela atualiza, ao passo que a realização é sempre reprodutora ou limitadora” (p. 137).

Desse modo, a forma-Homem deve ser grafada como forma-Homens, porque nela não há a oposição entre virtual e real; nela não há uma essência a mostrar o possível. Há, sim, a realidade do virtual, cuja plena realidade é constituída por relações diferenciais e distribuições de singularidades.

A forma-Homens é um acontecimento, cujo tour de force está presente nas obras de Deleuze, ao visitar o problema das forças atuantes no homem e das forças de fora (Orlandi, 1995) enlaçadas pelo campo transcendental sem sujeito.

A partir de agora, então, temos duas séries que se entrelaçam: 1) a diferença é marcada pelo traço distintivo ci/ç: diferenciar e diferençar; 2) a Ideia, ou a coisa em Ideia, é plenamente e completamente diferenciada, pois ela dispõe de relações e singularidades que se atualizarão sem semelhança nas qualidades e partes. Ou seja, a Ideia é plenamente diferenciada nela mesma, e por isso ela se atualiza por diferençação. 


\section{Considerações finais}

Ao imantar o positivo, a diferença, os fluxos, os agenciamentos - expressões essas que denotam o que é vivo, a dobra e a redobra, a duração e os signos geradores de potencialidades -, interrogou-se: como instalar na e pela multiplicidade das coisas vivas para aprendermos "a repetição como passagem de um estado das diferenças gerais à diferença singular, das diferenças exteriores à diferença interna em suma, a repetição como o diferenciador da diferença” (Deleuze, 1988, p. 136)? Por meio de Gabriel Tarde, buscou-se agenciar a dialética da diferença e da repetição, ao mostrar que a repetição é o diferenciador da diferença, o que lhe permitiu fundar uma microssociologia numa cosmologia. E na cosmologia de Gabriel Tarde, o decisivo se encontra no não equilíbrio, nas flutuações criadoras de possibilidades: a força do se. Dessa forma, delineou-se, pelas potências dos possíveis, a didática como diferenciador da diferença.

Em tudo o que precede, limitei-me a mostrar que a didática como diferenciador da diferença exerce um duplo papel, pois mostra o conteúdo da força e permite a realização das passagens entre virtual e atual.

A força, em nossa opinião (alicerçada nos diversos autores aqui citados), é o excesso do possível sobre o real. E a despeito de nem todos os possíveis se realizarem daí a finidade do Mundo -, a diferenciação nos revela que somos um composto de possíveis inúteis, por intermédio dos quais se desenrola por algum tempo uma mesma cadeia de possíveis utilizados. A prova de que os mais puros possíveis não são puros nadas é que eles lutam visivelmente para aparecer, e seu recalque é doloroso. Nesse sentido, a função da didática como diferenciador da diferença é ensinar que há um excesso do possível sobre o real, mesmo que a definição do desenvolvimento dos seres ocorra em função de seu aborto. Na formulação sintetizada por Gabriel Tarde (2007), “existir é diferir” (p. 98).

Como dramatização, a didática como diferenciador da diferença permite, pelo seu trabalho, que a Ideia, quando plenamente diferenciada nela mesma, disponha de relações e singularidades que se atualizarão sem semelhança nas qualidades, exercendo as passagens entre virtual e atual. Ela mostra, assim, a realidade do virtual, cuja plena realidade é constituída por relações diferenciais e distribuições de singularidades.

Pelo excesso de se existente no campo do virtual, para além do possível, é que se monta o suplemento a revelar uma ontologia da pura diferença. Tal operação de montagem é o trabalho possibilitado pela didática da diferença, ao realizar as passagens entre virtual e atual. 
Para a didática como diferenciador da diferença, a profundidade das coisas é atingida ao nos alargarmos para essas mesmas coisas para detectarmos nelas o diverso pelo diverso em sua especificidade, individualidade e heterogeneidade. Aguçar a fé perceptiva no sentido de notar que as causas - as quais são visíveis somente ao espírito - são múltiplas e multiplicadas pelo excesso de se, pelas múltiplas possibilidades. Por outro lado, os efeitos são diversos em suas realizações. Dessas duas formas do ato/potência, o múltiplo é afirmado. 0 múltiplo, como múltiplo, é objeto de afirmação; como o diverso, como diverso, objeto de alegria. 


\section{Referências bibliográficas}

Azanha, J. M. P. (2006). A formação do professor e outros escritos. São Paulo: Editora Senac São Paulo.

Bergson, H. (1983). O riso - ensaio sobre a significação do cômico (2a ed.). (N. C. Caixeiro, trad.). Rio de Janeiro: Zahar.

Cordeiro, J. F. P. (2003). Pedagogias multiplicadas: como as revistas masculinas e femininas produzem sujeitos. In J. Vaidergorn, \& L. M. Bertoni (Orgs.). Indústria cultural e educação: ensaios, pesquisas, formação (Vol. 1, pp. 31-59). Araraquara, SP: JM.

Cordeiro, J. F. P. (2006). Didática. São Paulo: Contexto.

Deleuze, G. (1988). Diferença e repetição. (L. B. L. Orlandi \& R. Machado, trads.) Rio de Janeiro: Graal.

Deleuze, G. (2006). A ilha deserta e outros textos. (D. Lapoujade, prep. ed., L. B. L. Orlandi, org. e ver. técnica). São Paulo: Iluminuras.

Deleuze, G. (2010). Proust e os signos (2a ed.) (A. Piquet \& R. Machado, trads.). Rio de Janeiro: Forense Universitária.

Foucault, M. (1996). O anti-Édipo: uma introdução à vida não-fascista (F. J. F. Ribeiro, trad.). Cad. Subj., num. esp., pp. 97-200.

Homero (1996). Odisséia. (M. O. Mendes, trad., A. M. Rodrigues, ed.). São Paulo: Ed. Universidade de São Paulo.

Kant, I. (1998). Manual dos cursos de lógica geral. (F. Castilho, trad., apresentação e guia). Campinas: IFCH-UNICAMP; Uberlândia: EDUFU.

Montaigne, M. E. de (1984). Ensaios (за ed.) (S. Milliet, trad.). São Paulo: Abril Cultural.

Nietzsche, F. (1976). Considerações intempestivas. (M. de Azevedo, trad.). Portugal Brasil: Editorial Presença/ Livraria Martins Fontes.

Noica, C. (2011). Diário filosófico. (E. M. D. Fonseca, trad., C. N. Manescu, conferência com o texto romeno). São Paulo: É Realizações.

Orlandi, L. B. L. (1995, novembro). Morte era para ele a marca da permanência. O Estado de S. Paulo, Cultura, p. D15.

Prigogine, I. (2002). Do ser ao devir. (M. L. F. R. Loureiro, trad.). São Paulo (SP): Editora UNESP; Belém (PA): Editora da Universidade Estadual do Pará.

Tarde, G. (2007). Monadologia e sociologia e outros ensaios. (P. Naves, trad., E. V. Vargas, organização e introdução). São Paulo: Cosac Naify.

Submetido à avaliação em 7 de fevereiro de 2014; aprovado para publicação em 3 de junho de 2014. 
138 